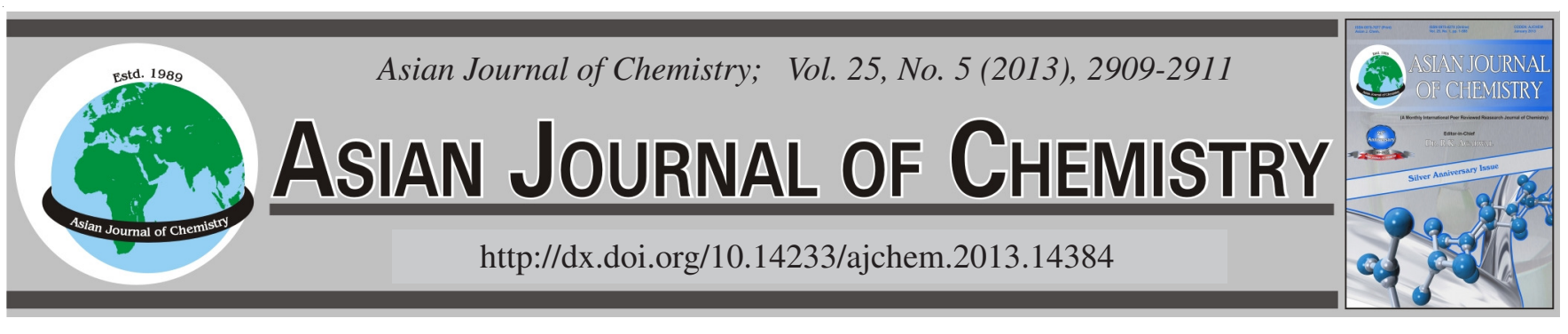

\title{
Effect of Different Anionic Ligands on Toxicity of Silver Nanoparticles
}

\author{
Shao-Feng Chen ${ }^{1}$ and Hongyin Zhang ${ }^{2, *}$
}

${ }^{1}$ Department of Chemical Engineering, Maoming Vocational Technical College, Maoming 525000, Guangdong Province, P.R. China ${ }^{2}$ College of Engineering, University of Rhode Island, Rhode Island 02881, USA

*Corresponding author: E-mail: hyz1983221@gmail.com

(Received: 31 July 2012;

Accepted: 27 November 2012)

AJC-12479

\begin{abstract}
Silver nanoparticle nanosuspension was prepared by Tollen's method using sodium citrate as stabilizing agent. Particle size and zeta potential of silver nanoparticles in different electrolyte solutions containing anionic ligands and humic acid solution were characterized by zetasizer. Dissolution of silver nanoparticels was evaluated using ICP-MS. Toxicity of silver nanoparticles on Escherichia coli were measured using a plate count method. The obtained results showed that toxicity of silver nanoparticles in electrolyte solution containing $\mathrm{Cl}^{-}$ligands was significantly reduced. Among all the conditions, toxicity of silver nanoparticles in humic acid solution was the lowest.

Key Words: Toxicity, Silver nanoparticles, Anionic ligands.
\end{abstract}

\section{INTRODUCTION}

Silver nanoparticles have been widely applied due to their excellent antimicrobial properties ${ }^{1,2}$. Several methods such as biological, chemical and physical methods can be used to chemically manufacture self-assembled silver nanoparticles. Currently, Tollens' method is frequently applied to synthesize silver nanoparticles ${ }^{3}$. The synthesis procedure include reducing $\mathrm{Ag}\left(\mathrm{NH}_{3}\right)_{2}{ }^{+}$in aqueous phase using an aldehyde. During the synthesis process, capping agents which include surfactants, polymers and other organic compounds were applied to increase the stability of silver nanoparticles in aqueous solutions. Among all the coatings, sodium citrate is an environmentally friendly coating and is the most widely used ${ }^{3,4}$.

Toxicity of silver nanoparticles in buffer solutions and bacterial culturing broth has been widely investigated. In addition, toxicity of silver nanoparticles in natural water conditions was also determined. Morones et al. ${ }^{5}$, and Sondi and Salopek-Sondi ${ }^{6}$, reported a size-dependent toxicity of silver nanoparticles on Escherichia coli (E. coli) in E. coli growth media. Gao et al. ${ }^{7}$ reported a decreased toxicity $\left(\mathrm{LC}_{50}=30.91\right.$ $\mu \mathrm{g} / \mathrm{L})$ on $E$. coli with increasing amount of natural organic matter present in different environmental relevant conditions.

Although several publications have reported the toxicity of silver nanoparticles in various conditions. A few studies investigated the effect of anionic ligands on their toxicity. The signi-ficance of this study lies in that (1) it could serve reference on the risk assessment of the release of silver nanoparticles in environmental water bodies; (2) it provides remediation approaches to reduce the toxicity of released silver nanoparticles in environmental relevant conditions; (3) it could guide the optimum amount and water condition on application of silver nanoparticles to reach their maximum disinfection performance.

In this study, particle sizes of silver nanoparticles with anionic ligands were evaluated using dynamic light scattering technique. Zeta potentials of silver nanoparticles were determined using zetasizer. Dissolution of silver nanoparticles was measured using ICP-MS. Toxicity of silver nanoparticles was evaluated using plate count method.

\section{EXPERIMENTAL}

Electrolyte solutions containing different anionic ligands $\left(\mathrm{NaCl}, \mathrm{NaNO}_{3}, \mathrm{NaSO}_{4}\right.$ and $\mathrm{Na}_{3} \mathrm{PO}_{4}$ ) were prepared. These four different electrolyte solutions were prepared using the same anionic concentration $(10 \mathrm{mg} / \mathrm{L})$. In addition, humic acid solution $(5 \mathrm{mg} / \mathrm{L})$ was prepared to mimic natural organic matter. The composition of synthetic water conditions are listed in Table-1.

\begin{tabular}{|c|c|c|}
\hline \multicolumn{3}{|c|}{$\begin{array}{c}\text { TABLE-1 } \\
\text { COMPOSTION OF SYNTHETIC WATER CONDITIONS }\end{array}$} \\
\hline Content & $\begin{array}{l}\text { Anion concentration } \\
(\mathrm{mg} / \mathrm{L})\end{array}$ & $\begin{array}{c}\text { Cation concentration } \\
(\mathrm{mg} / \mathrm{L})\end{array}$ \\
\hline $\mathrm{NaCl}$ & 10 & 6.5 \\
\hline $\mathrm{NaNO}_{3}$ & 10 & 3.7 \\
\hline $\mathrm{Na}_{2} \mathrm{SO}_{4}$ & 10 & 4.8 \\
\hline $\mathrm{Na}_{3} \mathrm{PO}_{4}$ & 10 & 10.6 \\
\hline Humic acid & $\mathrm{n} / \mathrm{a}$ & $\mathrm{n} / \mathrm{a}$ \\
\hline
\end{tabular}


Silver nanoparticles nanosuspension was prepared using Tollen's method described in previous study ${ }^{3}$. Silver nanoparticles were characterized using transmission electrion microscopy and UV-VIS spectrometer. Concentration of the prepared silver nanoparticles was measured using ICP-MS as total silver by dissolving silver nanoparticles with $2 \% \mathrm{HNO}_{3}$. Particle size and zeta potential of silver nanoparticles in different electrolyte solutions and humic acid (HA) solution were measured by zetasizer.

E. coli $1559^{7}$ was prepared using the suggested ATCC standard culturing procedure. Growth media were removed by centrifugation and the bacteria was resuspended in the individual electrolyte and humic acid solutions. Then, silver nanoparticles were added into the individual solutions to reach concentrations ranging from 0.1 to $10 \mathrm{mg} / \mathrm{L}$. Toxicity evaluations were conducted using the method previously described by Bae et al., ${ }^{8}$.

\section{RESULTS AND DISCUSSION}

Silver nanoparticles characterization: Silver nanoparticles nanosuspension was characterized by TEM and UVVis spectrometer (Fig. 1). UV-Vis spectrum shows that the surface plasmon resonance band of citrate stabilized silver nanoparticles located approximately at $400 \mathrm{~nm}$. This is in agreement with previous published studies ${ }^{3}$. TEM image shows that the silver nanoparticles exhibited spherical shape.
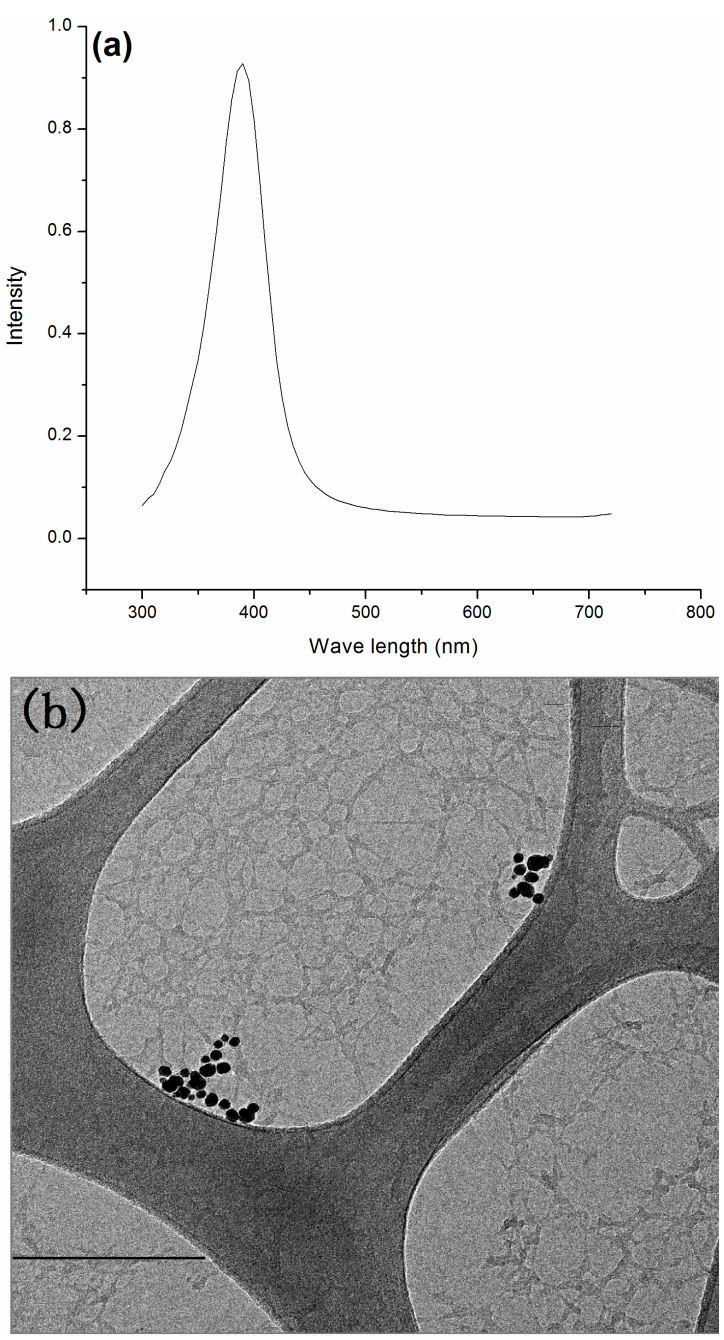

Fig. 1. UV-Vis spectrum (a) and TEM image (b) of citrate coated silver nanoparticles
Physicochemical properties of silver nanoparticles: Fig. 2 shows the particle size and zeta potential of silver nanoparticles in different electrolyte and humic acid solutions. Largest silver nanoparticles are observed in $\mathrm{Na}_{3} \mathrm{PO}_{4}$ solutions (29.9-30.1 nm). This observation is in agreement with DLVO theory which indicates that electrolyte solutions containing higher cation concentration (Table-1) could cause greater destabilizing effect.

Zeta potential indicates the stability of a colloidal system. A higher absolute value of zeta potential refers to a more stable nanosuspension. Zeta potential measurement in this study is consistent with the particle size measurement. As shown in Fig. 2, absolute zeta potential values of silver nanoparticles with anionic ligands $\mathrm{NO}_{3}{ }^{-}(-30.2 \mathrm{mV}--31.3 \mathrm{mV})$ are the higher among all anionic ligands, which indicate the highest stability. Absolute zeta potential of silver nanoparticles in humic acid solution is the highest among all water conditions $(-32.1 \mathrm{mV}$ $-33.7 \mathrm{mV})$. This is attributed to the steric repulsion exerted by the adsorption of humic acid molecules on the surface of silver nanoparticles.
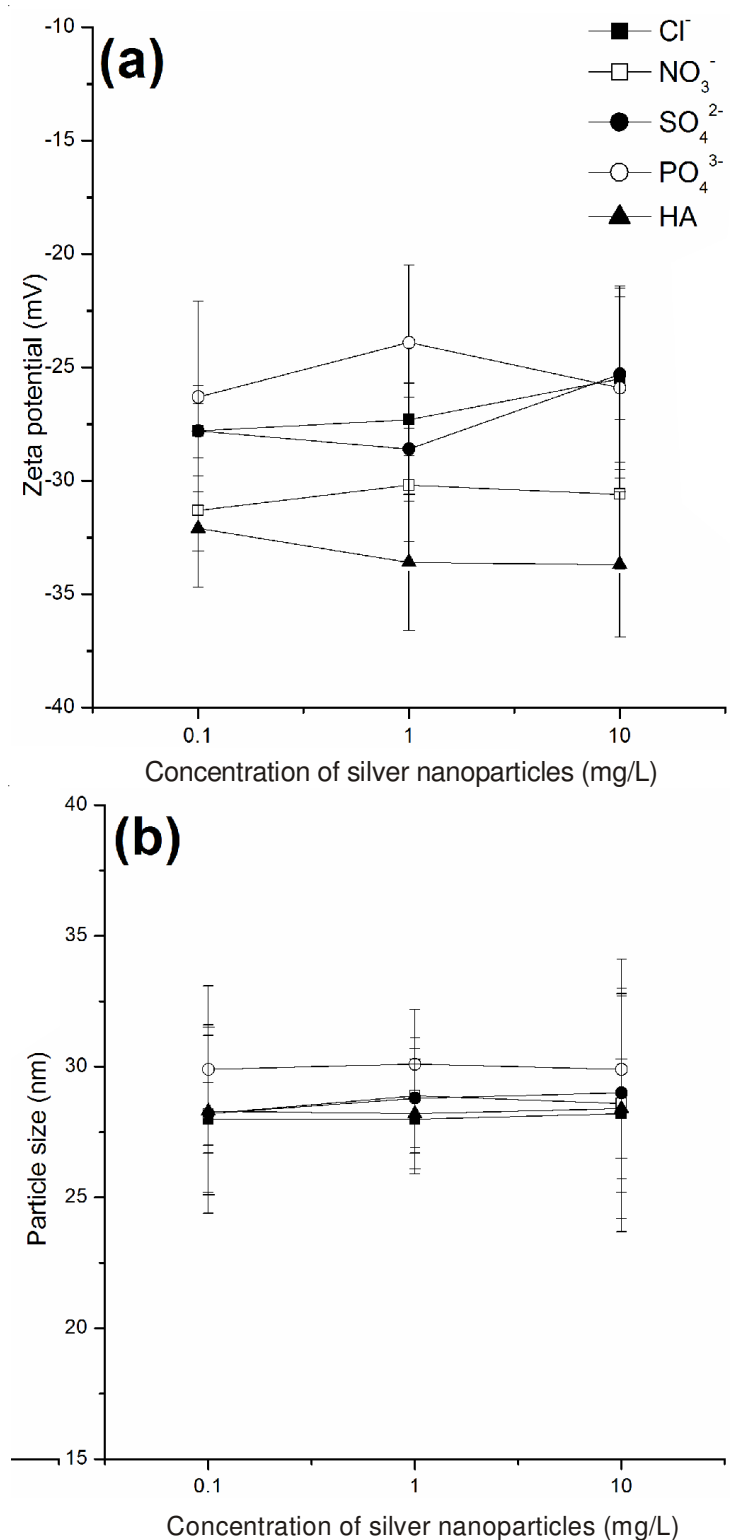

Fig. 2. Zeta potential (a) and particle size (b) of silver nanoparticles in different water conditions 
Toxicity of silver nanoparticles in different water conditions: Fig. 3 presents toxicity evaluation of silver nanoparticles in different water conditions. In different electrolyte solutions, silver nanoparticles with $\mathrm{Cl}^{-}$ligand demonstrates the lowest toxicity (20\%-93\%) among all anionic ligands. This might be attributed to the toxicity reduction due to the reaction between $\mathrm{Ag}^{+}$and $\mathrm{Cl}^{-}$(eq. 1) as previous studies have indicated that the toxicity of silver nanoparticles comes from $\mathrm{Ag}^{+}$ion?:

$$
\mathrm{Ag}^{+}+\mathrm{Cl}^{-} \rightarrow \mathrm{AgCl}_{\mathrm{s}}
$$

Toxicity of silver nanoparticles in humic acid solution is lowest (19 \%-83\%) among all water conditions. This is because of the formation of physical barriers between silver nanoparticles and bacteria by the steric repulsion due to the sorption of humic acid molecules onto silver nanoparticle surface $^{10-12}$.

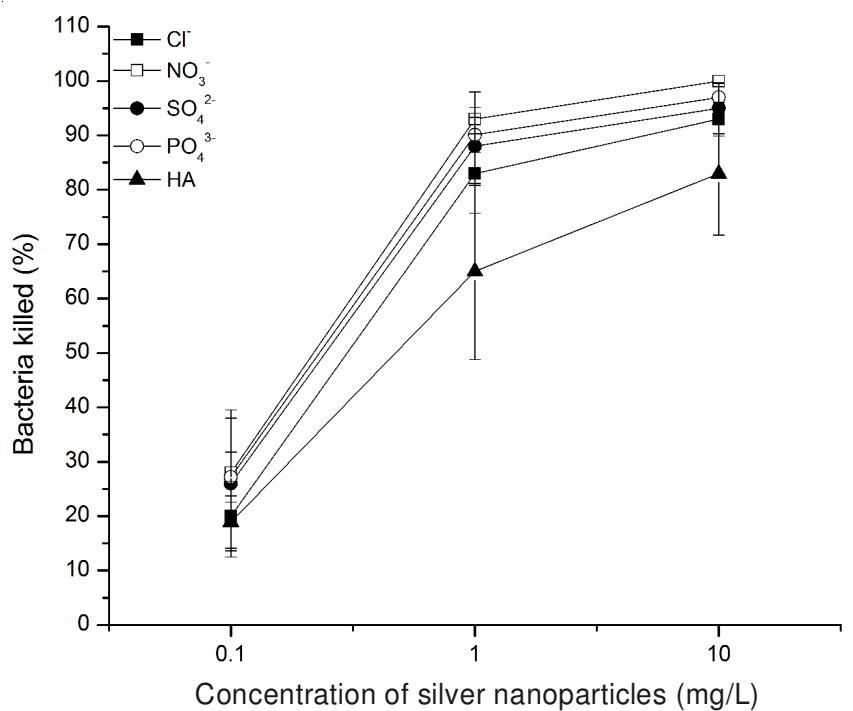

Fig. 3. Toxicity of silver nanoparticles in different water conditions

\section{Conclusion}

This study has shown the physicochemical properties and toxicity of silver nanoparticles with various ligands in different water conditions. Particle size and zeta potential of silver nanoparticles increased with increasing negative charges of the anionic ligands. Toxicity evaluations indicated that silver nanoparticles in $\mathrm{NaCl}$ and humic acid solutions were less toxic to E. coli.

\section{REFERENCES}

1. L. Maleknia, A. Aala and K. Yousefi, Asian J. Chem., 22, 5925 (2010).

2. Ratyakshi and R. Chauhan, Asian J. Chem., 21, S113 (2009).

3. L. Kvitek, M. Vanickova, A. Panacek, J. Soukupova, M. Dittrich, E. Valentova, R. Prucek, M. Bancirova, D. Milde and R. Zboril, J. Phys. Chem., 113, 4296 (2009).

4. K.A. Huynh and K.L. Chen, Environ. Sci. Technol., 45, 5564 (2011).

5. J. Morones, J. Elechiguerra, A. Camacho, K. Holt, J.B. Kouri, J.T. Ramírez and M.J. Yacaman, Nanotechnology, 16, 2346 (2005).

6. I. Sondi and B. Salopek-Sondi, J. Colloid Interf. Sci., 275, 177 (2004).

7. J. Gao, S. Youn and A. Hovsepyan, V.L. Llaneza, Y. Wang, G. Bitton and J.-C.J. Bonzongo, Environ. Sci. Technol., 43, 3322 (2009).

8. E. Bae, H. Park, J. Lee, Y. Kim, J. Yoon, K. Park, K. Choi and J. Yi, Environ. Toxicol. Chem., 29, 2154 (2010).

9. J. Liu and R.H. Hurt, Environ. Sci. Technol., 44, 2169 (2010).

10. J. Fabrega, S.R. Fawcett, J.C. Renshaw and J.R. Lead, Environ. Sci. Technol., 43, 7285 (2009).

11. S. Chen and H. Zhang, Adv. Nat. Sci: Nanosci. Nanotechnol., 3, 1 (2012).

12. H. Zhang, S. Chen and Q. Lin, Chin. J. Inorg. Chem., 28, 833 (2012). 